\title{
Hypercholesterolemia due to cholesterol 7alpha-hydroxylase deficiency
}

INSERM

\section{Source}

INSERM. (1999). Orphanet: an online rare disease and orphan drug data base. Hypercholesterolemia due to cholesterol 7alpha-hydroxylase deficiency. ORPHA:209902

Hypercholesterolemia due to cholesterol 7alpha-hydroxylase deficiency is a rare, genetic, sterol metabolism disorder characterized by increased LDL cholesterol serum levels (which are resistant to treatment with 3-hydroxy-3-methylglutaryl-coenzyme A reductase inhibitors), hypertrig liceridemia, and decreased rate of bile acid excretion, resulting from cholesterol 7alpha-hydroxylase deficiency. Premature gallstone disease and/or premature coronary and peripheral vascular disease are frequently associated. 